\title{
Umbilical cord blood cells capable of engrafting in primary, secondary, and tertiary xenogeneic hosts are preserved after ex vivo culture in a noncontact system
}

Ian D. Lewis, Graca Almeida-Porada, Jingbo Du, Ihor R. Lemischka, Kateri A. Moore, Esmail D. Zanjani and Catherine M. Verfaillie

Updated information and services can be found at:

http://bloodjournal.hematologylibrary.org/cgi/content/full/97/11/3441

Articles on similar topics may be found in the following Blood collections:

Hematopoiesis and Stem Cells (2715 articles)

Information about reproducing this article in parts or in its entirety may be found online at:

http://bloodjournal.hematologylibrary.org/misc/rights.dtl\#repub_requests

Information about ordering reprints may be found online at:

http://bloodjournal.hematologylibrary.org/misc/rights.dtl\#reprints

Information about subscriptions and ASH membership may be found online at:

http://bloodjournal.hematologylibrary.org/subscriptions/index.dtl

Blood (print ISSN 0006-4971, online ISSN 1528-0020), is published semimonthly by the American Society of Hematology, 1900 M St, NW, Suite 200, Washington DC 20036.

Copyright 2007 by The American Society of Hematology; all rights reserved.

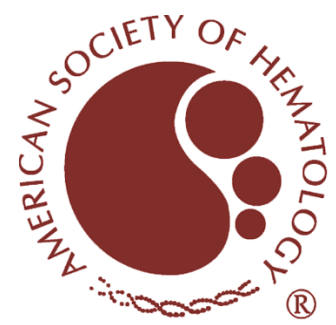




\section{Umbilical cord blood cells capable of engrafting in primary, secondary, and tertiary xenogeneic hosts are preserved after ex vivo culture in a noncontact system}

Ian D. Lewis, Graca Almeida-Porada, Jingbo Du, Ihor R. Lemischka, Kateri A. Moore, Esmail D. Zanjani, and Catherine M. Verfaillie

This report describes stroma-based and stroma-free cultures that maintain longterm engrafting hematopoietic cells for at least 14 days ex vivo. Umbilical cord blood (UCB) CD $34^{+}$cells were cultured in transwells above AFT024 feeders with fetal-liver-tyrosine-kinase (FL) + stem cell factor (SCF) + interleukin 7 (IL-7), or FL + thrombopoietin (Tpo). CD34 ${ }^{+}$progeny were transplanted into nonobese diabeticsevere combined immunodeficiency (NOD-SCID) mice or preimmune fetal sheep. SCID repopulating cells (SRC) with multilineage differentiation potential were maintained in FL-SCF-IL-7 or FL-Tpo containing cultures for up to 28 days. Marrow from mice highly engrafted with uncultured or expanded cells induced multilineage human hematopoiesis in $50 \%$ of secondary but not tertiary recipients. Day 7 expanded cells engrafted primary, secondary, and tertiary fetal sheep. Day 14 expanded cells, although engrafting primary and to a lesser degree secondary fetal sheep, failed to engraft tertiary recipients. SRC that can be transferred to sec- ondary recipients were maintained for at least 14 days in medium containing glycosaminoglycans and cytokines found in stromal supernatants. This is the first demonstration that ex vivo culture in stroma-noncontact and stroma-free cultures maintains "long-term" engrafting cells, defined by their capacity to engraft secondary or tertiary hosts. (Blood. 2001; 97:3441-3449)

() 2001 by The American Society of Hematology

\section{Introduction}

Ex vivo expansion of hematopoietic cells is needed not only for gene transfer ${ }^{1-3}$ and tumor purging, ${ }^{4,5}$ but also to amplify the number of hematopoietic stem cells (HSC), especially in umbilical cord blood (UCB) grafts. The use of UCB as a source of HSC is increasing because there is less incidence of graft-versus-host disease after UCB transplantation. ${ }^{6,7}$ This allows use of grafts with greater HLA disparity and therefore increases the number of grafts available for transplantation. However, absolute HSC dose is a limiting factor in the use of UCB as a graft for adult transplant recipients.

Hematopoiesis is a tightly regulated process in which HSC give rise to all components of the hematopoietic system for the lifetime of the individual. Properties of HSC are self-renewal, multilineage differentiation capacity, and ability to repopulate a myeloablated host. Assays such as the long-term culture-initiating cell (LTC-IC) ${ }^{8}$ and extended LTC-IC assays ${ }^{9}$ measure the ability of cells to generate myeloid progenitors after a prolonged period in culture. However, these assays do not measure self-renewal, multilineage potential, or engraftment potential of progenitors. Although the recent development of the myeloid-lymphoid initiating cell assay (ML-IC) ${ }^{10}$ and the self-renewing ML-IC assay (H. Liu and C.M.V., submitted) has allowed in vitro observation of multilineage differentiation and self-renewal of single cells, assessment of the engrafting ability of human HSC requires transplant models. Several xenogeneic models have been developed, including trans- plantation into the humanized severe combined immunodeficiency (SCID) mouse, ${ }^{11}$ into nonobese diabetic (NOD)-SCID mice, ${ }^{12}$ the Beige-Nude-Xid (BNX) mouse ${ }^{13}$ and preimmune fetal sheep. ${ }^{14,15}$ The engrafting human cell in NOD-SCID or SCID mice has been defined as the SCID-repopulating cell (SRC) or competitive repopulating unit (CRU), a cell that may be more primitive than LTC-IC. ${ }^{11}$ In addition, several groups have used autologous or allogeneic transplantation in rhesus or baboon monkeys as a model for human stem cells. ${ }^{16,17}$ Each of these assays has its own advantages and disadvantages. How efficient they are at measuring human HSC and how they compare with in vitro assays that measure primitive progenitors is not known.

Ex vivo culture systems can be used to expand committed progenitors or accessory cells. ${ }^{18,19}$ Here we focused on the use of ex vivo expansion cultures to increase the number of long-term repopulating cells that have self-renewal and multilineage differentiation capacity. Several ex vivo expansion systems have been developed, including cytokine-rich stroma-free systems that may or may not contain serum or systems in which hematopoiesis is supported by a stromal feeder. The majority of studies in which progenitors are cultured in stroma-free, serum-free, or serumcontaining cytokine-supplemented conditions show that culture for less than 6 days results in a modest increase in SRC frequency, but loss of SRC if the cultures are extended for longer periods. ${ }^{15,20,21}$ One recent study from Piacibello and coworkers reported a more
From the Stem Cell Institute, the Department of Medicine and Cancer Center, University of Minnesota, Minneapolis; the Department of Medicine, the Department of Veterans Affairs Medical Center, University of Nevada, Reno; and the Department of Molecular Biology, Princeton University, Princeton, NJ.

Submitted May 30, 2000; accepted February 6, 2001.

Supported in part by: R01-DK-53673 (to C.M.V.), P01-CA-65493 (to C.M.V.), HL-52955 (to E.D.Z.), HL-49042 (to E.D.Z.), DK-51427 (to E.D.Z.), the Veterans Administration, and Fairview-University of Minnesota. C.M.V. is a
Scholar of the Leukemia Society of America.

Reprints: Catherine M. Verfaillie, Box 806 UMHC, 420 Delaware St SE, Minneapolis, MN 55455; e-mail: verfa001@tc.umn.edu.

The publication costs of this article were defrayed in part by page charge payment. Therefore, and solely to indicate this fact, this article is hereby marked "advertisement" in accordance with 18 U.S.C. section 1734.

(c) 2001 by The American Society of Hematology 
From www.bloodjournal.org at kuleuven on October 6, 2010. For personal use only.

than 50-fold expansion of SRC when UCB CD34+ cells were cultured for 6 to 10 weeks in a human serum-containing system with fetal-liver-tyrosine-kinase-ligand (FL), thrombopoietin (Tpo), and/or stem cell factor (SCF) and interleukin 6 (IL-6). ${ }^{22}$

A number of murine-derived stromal cell lines have been cloned that support not only murine repopulating cells but also primitive human hematopoietic progenitors. ${ }^{10,23-25}$ However, coculture of human cells with the murine feeder will not be suitable for clinical ex vivo expansion. We developed noncontact cultures in which cells are cultured in a transwell above a stromal feeder and have shown that primitive LTC-IC, natural killer culture-initiating cell (NK-IC) and ML-IC are maintained to the same or greater degree than when cells are cocultured in contact with feeders. ${ }^{10,26}$ Because human $\mathrm{CD}_{3} 4^{+}$cells remain separated from the murine feeder, noncontact cultures avoid some of the practical problems associated with contact cultures.

We describe here the ability of the murine fetal liver cell line, AFT024, to maintain/expand human $\mathrm{UCB} \mathrm{CD}^{3} 4^{+}$repopulating cells assayed in the NOD-SCID mouse and the fetal sheep model. We found that culture of UCB CD34 ${ }^{+}$cells for up to 28 days in an AFT024 noncontact system supplemented with a combination of early acting cytokines, including SCF, FL, Tpo, and IL-7, maintains repopulating cells in NOD/SCID as well as fetal sheep. We provide the first evidence that ex vivo expanded cells continue to contain "long-term" repopulating cells because they can be serially passaged to secondary NOD-SCID mice and secondary and tertiary fetal sheep.

\section{Materials and methods}

\section{Isolation of cells}

After informed consent was obtained, UCB cells were collected by standard procedures used for UCB banking. Mononuclear cells (MNC) were obtained by Ficoll-Hypaque (Sigma Diagnostics, St Louis, MO) density gradient centrifugation. $\mathrm{CD}_{4}{ }^{+}$cells were isolated by magnetic cell separation (MACS system; Miltenyi Biotec, Auburn, CA). Procedures were performed as per manufacturer's recommendations. $\mathrm{CD}_{3} 4^{+}$cells were cryopreserved in 10\% dimethylsulfoxide (Sigma), $20 \%$ fetal calf serum (FCS, Hyclone Laboratories, Logan, UT) by controlled-rate freezing. Following thawing, samples were usually pooled to provide sufficient cell numbers for each experiment.

\section{Stromal feeder}

The murine fetal liver cell line, AFT024 (a kind gift from Dr I. Lemischka, Princeton University, Princeton, $\mathrm{NJ})^{27}$ was maintained at $33^{\circ} \mathrm{C}$ in Dulbecco modified Eagle medium (DMEM; Gibco-BRL, Grand Island, NY) supplemented with $20 \% \mathrm{FCS}, 50 \mu \mathrm{mol} / \mathrm{L}$ 2-mercaptoethanol (2-ME, Biorad, Hercules, CA). Cells were subcultured in 6- or 96-well plates (Costar, Cambridge, MA), grown to confluency, and then irradiated at $2000 \mathrm{rads}$ using a Mark 1 Cesium irradiator (Shepard, Glendale, CA) 24 hours prior to establishing cultures, as previously described. ${ }^{10}$

\section{Expansion cultures}

Noncontact cultures. Cells were plated in collagen coated transwells with a 0.4- $\mu \mathrm{m}$ microporous filter (Transwell-COL, Costar) above AFT024 feeders (noncontact) established in 6-well plates (Costar) as previously described. ${ }^{28}$ Initial cell concentration was $40000 \mathrm{CD} 34^{+}$cells $/ \mathrm{mL}$ for 7-day cultures and 20000 cells/mL for 14-day cultures. Individual wells contained $5 \mathrm{~mL}$ medium of which $2 \mathrm{~mL}$ contained the cells within the transwell. Medium consisted of RPMI supplemented with 20\% FCS, 1000 $\mathrm{U} / \mathrm{mL}$ penicillin, $100 \mathrm{U} / \mathrm{mL}$ streptomycin (Gibco-BRL), and $50 \mu \mathrm{mol} / \mathrm{L}$ 2-ME. Cytokine cocktails incorporated $10 \mathrm{ng} / \mathrm{mL}$ FL (Immunex, Seattle,
WA), 10 ng/mL SCF (Amgen, Thousand Oaks, CA), 10 ng/mL IL-7 (R\&D Systems, Minneapolis, MN), and/or $10 \mathrm{ng} / \mathrm{mL}$ Tpo (Amgen). Medium was added once at day 0 and changed every 7 days for 14- and 28-day cultures.

MV8 stroma-free cultures. Medium consisted of RPMI $+20 \%$ FCS with $250 \mathrm{pg} / \mathrm{mL}$ granulocyte colony-stimulating factor (G-CSF) (Amgen), $200 \mathrm{pg} / \mathrm{mL}$ macrophage-inflammatory protein-1 $\alpha$ (MIP-1 $\alpha$; R\&D Systems), $1 \mathrm{ng} / \mathrm{mL}$ IL-6 (R\&D Systems), $10 \mathrm{ng} / \mathrm{mL}$ monocyte-chemoattractant protein-1 (MCP-1; R\&D Systems), $10 \mathrm{ng} / \mathrm{mL}$ vascular endothelial cell growth factor (VEGF) (a kind gift from Dr S. Ramakrishnan, University of Minnesota) $2 \mathrm{ng} / \mathrm{mL}$ IL-8 (R\&D Systems), and $10 \mu \mathrm{g} / \mathrm{mL}$ N-desulfated O-sulfated heparin (Seikagaku America, Falmouth, MA). ${ }^{29,30}$ Cultures also contained $10 \mathrm{ng} / \mathrm{mL}$ Tpo, $20 \mathrm{ng} / \mathrm{mL}$ FL, $20 \mathrm{ng} / \mathrm{mL}$ SCF, and $20 \mathrm{ng} / \mathrm{mL}$ IL-7. Media were replenished every 48 hours.

\section{LTC-IC and colony-forming cell assays}

Thawed $\mathrm{CD}_{3} 4^{+}$cells (day 0) and $\mathrm{CD} 34^{+}$cell progeny from expansion cultures were plated in limiting dilutions in LTC-IC, as well as in colony-forming cell (CFC) assays. LTC-IC assays were performed as described. $^{28,31}$ For LTC-IC assays, cells were plated in 4 dilutions of 22 replicates on preirradiated AFT024-coated 96-well plates. Medium consisted of Iscoves modified Dulbecco medium (IMDM) supplemented with $12.5 \%$ FCS, $12.5 \%$ horse serum (Stem Cell Technologies, Vancouver, BC, Canada), $1000 \mathrm{U} / \mathrm{mL}$ penicillin, $100 \mathrm{U} / \mathrm{mL}$ streptomycin, $2 \mu \mathrm{mol} \mathrm{L}$ glutamine (Gibco-BRL), and $10^{-6} \mu \mathrm{mol}$ hydrocortisone. Cultures were maintained for 5 weeks with a half-medium change weekly. Medium was then completely removed and replaced with clonogenic methylcellulose medium consisting of $1.12 \%$ methylcellulose (Fisher, Chicago, IL), IMDM, $30 \%$ FCS, $3 \mathrm{U} / \mathrm{mL}$ erythropoietin (Amgen), and supernatant of the bladder cell carcinoma cell line 5637 (7.5\%). After 2 weeks, wells were evaluated for the presence or absence of hematopoietic colonies and scored as positive or negative, respectively. LTC-IC frequency was then calculated according to Poisson statistics.

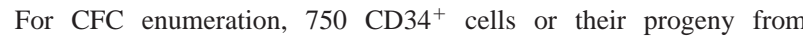
expansion cultures were plated in methylcellulose containing IMDM supplemented with $30 \%$ FCS, 3 IU erythropoietin (Amgen), $10 \mathrm{ng} / \mathrm{mL}$ each of IL-3 (R\&D Systems), G-CSF, and granulocyte-macrophage-CSF (GMCSF; Immunex) as previously described. ${ }^{31}$ Cultures were incubated in a humidified atmosphere at $37^{\circ} \mathrm{C}$ and $5 \% \mathrm{CO}_{2}$ and evaluated after 14 days for the presence of colony-forming units-granulocyte macrophage (CFU-GM) or burst forming units-erythroid (BFU-E).

\section{Transplantation experiments}

NOD-SCID recipients. A breeding colony of NOD-SCID mice was established from mice obtained from the Jackson Laboratories (Bar Harbor, $\mathrm{ME}$ ). Mice were kept in specific pathogen-free conditions and maintained on acidified water and autoclaved food. Trimethoprim $60 \mathrm{mg}$ and sulfamethoxazole $300 \mathrm{mg}$ (Hoffmann-La Roche, Nutley, NJ) per $100 \mathrm{~mL}$ water was given twice weekly. At 6 to 8 weeks of age, mice were irradiated with 300 to $325 \mathrm{cGy}$ at $57 \mathrm{cGy} / \mathrm{min}$ by a Mark 1 Cesium irradiator. Transplantation of UCB cells by tail vein injection occurred 24 hours after irradiation. Cell doses ranged from 25 to $150 \times 10^{3} \mathrm{CD} 34^{+}$cells on day 0 (ie, uncultured) or the progeny of an identical number of cultured cells on days 7,14 , or 28 . Six weeks after transplantation, mice were killed by cervical dislocation. Bone marrow (BM) was obtained by flushing femurs and tibias with IMDM $20 \%$ FCS. Cells from engrafted animals were then used for either secondary transplant experiments or extended phenotypes. When more than $2 \%$ human $\mathrm{CD} 45^{+}$cells were present in the murine marrow, cells from 2 femurs and 2 tibias were transplanted into individual secondary mouse recipients.

Assessment of donor cell engraftment was by detection of the humanspecific pan-leukocyte antigen CD45 (Becton Dickinson Immunocytometry Systems, San Jose, CA) conjugated to fluorescein isothiocyanate (FITC) or peridinin chlorophyll (PerCP). Three-color phenotyping was performed by staining cells with antihuman CD45 PerCP (Becton Dickinson), antimouse CD45 FITC (Pharmingen, San Diego, CA), and antihuman CD3 phycoerythrin (PE), CD14 PE, CD19 PE, CD33 PE, or CD34 PE (all from Becton Dickinson). Appropriate isotype controls were used. The frequency of the engrafting human cell in the mouse, defined as an SRC, was calculated by 


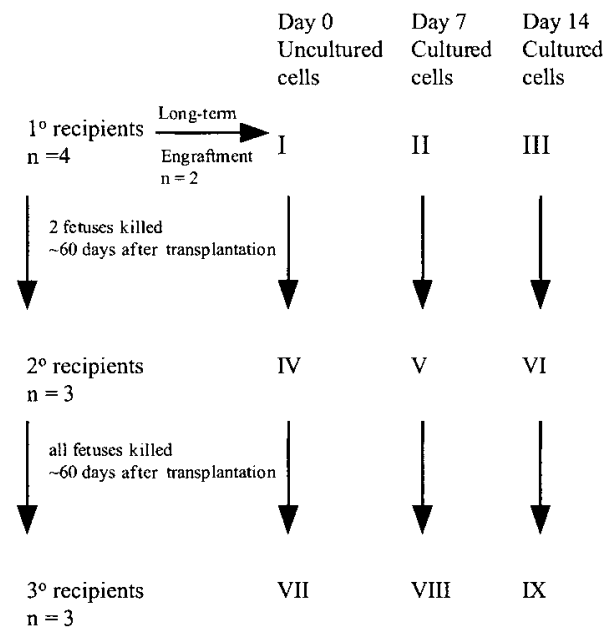

Figure 1. Set up of fetal sheep experiments. CB CD34+ cells $(100000)$ were injected into 4 fetal sheep (group I). Two sheep were allowed to be born and followed long-term. Sixty days after transplantation, 2 fetuses were killed and the human $\mathrm{CD} 45^{+}$cells pooled and then injected into 3 secondary recipients (group IV). These recipients were killed at 60 days, BM pooled, and injected into 3 tertiary recipients (group VII). A similar protocol was followed with the cells cultured for 7 and 14 days.

limiting dilution analysis. Mice were infused with increasing cell numbers and engraftment defined as detection of more than $0.5 \%$ human $\mathrm{CD}^{+} 5^{+}$ cells. SRC frequency was calculated by Poisson statistics. ${ }^{12}$

Fetal sheep recipients. Freshly uncultured or cultured cells were suspended in IMDM $+20 \%$ FCS, $10 \mathrm{ng} / \mathrm{mL}$ FL, SCF, and IL-7, and shipped overnight at room temperature to the University of Nevada, Reno. ${ }^{32}$ Fifty (group X) to 100 (group I) $\times 10^{3}$ uncultured $\mathrm{CD} 34^{+}$cells or the progeny of an identical number of cells cultured for 7 (group XI and II) or 14 (group XII and III) days were injected into preimmune (day 57-62 of gestation) fetal sheep recipients using the amniotic bubble procedure as described (Figure 1). ${ }^{14,15}$ In some experiments, animals were killed 60 days after transplantation and BM analyzed for human cells. The BM also served as the source of $\mathrm{CD}_{4} 5^{+}$cells for transplant into secondary recipients. Alternatively, animals were allowed to be born and BM examined 6 months after transplantation. For secondary transplants, human $\mathrm{CD} 45^{+}$cells were isolated from the BM of primary recipients from groups I, II, and III at 60 days after transplant by panning as described previously.14,15 The CD45 cells from the 2 animals from each group were pooled, analyzed for $\mathrm{CD}_{3} 4^{+}$ cell content, and injected into 3 secondary fetal recipients (group I, group IV, group II, group V, group III, group VI). Animals were killed on day 60 after transplantation and the BM cells were analyzed for the presence of human cells. Marrow of these secondary recipients served as the source of $\mathrm{CD} 45^{+}$cells transplanted into tertiary recipients. Because the number of $\mathrm{CD} 45^{+}$cells was extremely low in the secondary recipients in group VI, whole marrow was transplanted in tertiary recipients (group IV, group VII, group V, group VIII, group VI, group IX). All recipients were killed on day
60 after transplantation and the BM cells were analyzed for the presence of human cells.

For assessment of donor cell engraftment, BM MNC from the fetal and newborn sheep transplanted with human cells were analyzed for the presence of human cells by flow cytometry as previously described. ${ }^{32,33}$ Briefly, MNC were isolated from BM by hypotonic lysis of contaminating red cells. Antibodies specific for human CD3, CD20, CD33, CD34, CD45, and glycophorin A (Becton Dickinson) were conjugated to either FITC or PE. In each sample, $5 \times 10^{5}$ cells were labeled and expression of each antigen compared to the appropriate nonbinding isotype-matched control. Expression levels of $0.2 \%$ or more could be detected.

In addition, BM MNC were cultured in methylcellulose $\left(0.4-2 \times 10^{5}\right.$ cells $/ \mathrm{mL}$ ) with supplemental erythropoietin (2 IU/mL), IL-3 $(5 \mathrm{ng} / \mathrm{mL})$, and GM-CSF $(5 \mathrm{ng} / \mathrm{mL})$ and human CFU-GM and CFU-Mix enumerated as described. ${ }^{32}$

\section{Statistical analysis}

Results of experimental points obtained from multiple experiments are expressed as the mean \pm SEM

\section{Results}

In a first series of experiments, we examined if culture in a noncontact system using AFT024 as a stromal feeder supports $\mathrm{UCB} \mathrm{CD} 34^{+}$cells that engraft NOD-SCID mice. Freshly thawed $\mathrm{UCB} \mathrm{CD} 34^{+}$cells were transplanted in limiting dilutions into NOD-SCID recipients. Alternatively, identical numbers of $\mathrm{CD}_{3} 4^{+}$ cells were cultured for 7 and 14 days in AFT024 noncontact cultures supplemented with FL, SCF, and IL-7, and progeny of limiting dilutions of $\mathrm{CD} 34^{+}$cells transplanted in NOD-SCID mice. The cytokine combination was chosen based on studies from our group demonstrating that BM LTC-IC and NK-IC can be expanded under these conditions ${ }^{10}$ (Table 1 ).

When transplanted with uncultured cells, 43 of $55(78 \%)$ mice engrafted at levels of $0.5 \%$ to $26 \%$ (mean $6.5 \%$ ). A higher mean engraftment level was noted with increasing cell doses although the frequency of engraftment did not change with increasing cell doses. The SRC frequency was $3.4 / 10^{5}$ uncultured $\mathrm{CD}^{2} 4^{+}$cells $(2.3-5.1$, $95 \%$ confidence limits). When transplanted with cells cultured for 7 days, 41 of $55(75 \%)$ mice engrafted at levels of $0.5 \%$ to $26 \%$ (mean $4.6 \%$ ). The effect of cell dose on engraftment was not as apparent at this time point, although there was a trend toward a higher level of engraftment with increasing cell dose. The SRC frequency was $2.7 / 10^{5} \mathrm{CD}^{+}{ }^{+}$cells $(1.8-4.1,95 \%$ confidence limits). When transplanted with cells cultured for 14 days, 34 of 43 (79\%) mice engrafted at levels of $1.0 \%$ to $57 \%$ (mean $7.2 \%$ ). No

Table 1. Engraftment of freshly thawed and ex vivo-expanded umbilical cord blood CD $34^{+}$cells in nonobese diabetic-severe combined immunodeficiency recipients

\begin{tabular}{|c|c|c|c|c|c|c|c|c|c|}
\hline \multirow[b]{2}{*}{ Cell dose $\times 10^{3}$} & \multicolumn{3}{|c|}{ Day 0 engraftment } & \multicolumn{3}{|c|}{ Day 7 engraftment* } & \multicolumn{3}{|c|}{ Day 14 engraftment* } \\
\hline & $\mathrm{N} \dagger$ & Mean‡ & Range‡ & $\mathrm{N} \dagger$ & Mean‡ & Range‡ & $\mathrm{N} \dagger$ & Mean‡ & Rangeł \\
\hline $20-25$ & $6 / 9$ & 1.7 & $0-6$ & $7 / 9$ & 4.1 & $0-21$ & $4 / 8$ & 2.4 & $0-9$ \\
\hline $26-50$ & $13 / 15$ & 4.7 & $0-16$ & $10 / 12$ & 3.8 & $0-15$ & $11 / 15$ & 4.7 & $0-21$ \\
\hline $51-75$ & $11 / 16$ & 7.4 & $0-21$ & $10 / 15$ & 2.7 & $0-24$ & $9 / 9$ & 14.7 & $1-57$ \\
\hline $76-100$ & $9 / 11$ & 9.5 & $0-26$ & $9 / 14$ & 7.3 & $0-26$ & $5 / 6$ & 8.4 & $0-42$ \\
\hline $101-150$ & $4 / 4$ & 12.5 & $7-17$ & $5 / 5$ & 6 & $2-10$ & $5 / 5$ & 7.2 & $1-19$ \\
\hline
\end{tabular}

Sublethally irradiated nonobese diabetic-severe combined immunodeficiency (NOD-SCID) mice were transplanted with increasing doses of fresh or ex vivo-cultured umbilical cord blood (UCB) CD34+ cells from multiple donors. After 6 weeks, marrow was obtained and the frequency of human CD45 ${ }^{+}$cells determined by flow cytometry. Results are pooled from 4 independent experiments. At the lower cell doses, 2 to 4 mice were examined per experiment per point.

${ }^{*}$ Cells were expanded for 7 or 14 days in AFT024-noncontact culture supplemented with fetal-liver-tyrosine-kinase-ligand (FL), stem cell factor (SCF), and interleukin 7 (IL-7). †Number of animals engrafted/number of animals that were transplanted.

fPercent human CD45 ${ }^{+}$cells in mouse marrow. 
From www.bloodjournal.org at kuleuven on October 6, 2010. For personal use only.

Table 2. Expansion of total nucleated cells, CD34+ cells, colony-forming cells, and long-term culture-initiating cells under AFT024 noncontact or stroma-free conditions

\begin{tabular}{|c|c|c|c|c|c|c|c|c|}
\hline \multirow{2}{*}{$\begin{array}{l}\text { Culture } \\
\text { condition }\end{array}$} & \multicolumn{4}{|c|}{ Day 7 fold expansion } & \multicolumn{4}{|c|}{ Day 14 fold expansion } \\
\hline & TNC & $\mathrm{CD}_{3} 4^{+}$ & CFC & LTC-IC & TNC & $\mathrm{CD}_{4} 4^{+}$ & CFC & LTC-IC \\
\hline FS7-SNC* & $10.8 \pm 4.1$ & $3.2 \pm 1.5$ & $4.0 \pm 0.3$ & $2.5 \pm 0.8$ & $76.1 \pm 11.2$ & $15.8 \pm 10.1$ & $1.8 \pm 0.3$ & $3.0 \pm 0.6$ \\
\hline FT-SNC* & $10.2 \pm 5.8$ & $2.2 \pm 1.2$ & $3.9 \pm 0.8$ & $4.7 \pm 0.8$ & $36.6 \pm 8.1$ & $7.9 \pm 4.7$ & $2.5 \pm 0.3$ & $2.4 \pm 0.9$ \\
\hline Stroma free† & $14.8 \pm 3.0$ & $1.1 \pm 0.2$ & $2.2 \pm 0.6$ & $3.6 \pm 1.1$ & $185 \pm 97$ & $2.0 \pm 2.0$ & $1.0 \pm 0.7$ & $2.4 \pm 0.7$ \\
\hline
\end{tabular}

UCB CD34+ cells were cultured in AFT024 noncontact culture or stroma-free culture as described in "Materials and methods." After 1 and 2 weeks, cells were harvested and analyzed for the number of CD34+ cells, colony-forming cell (CFC), and long-term culture-initiating cell (LTC-IC). Number of CFC in uncultured UCB CD34 ${ }^{+}$cells $=13.9 \%$ $\pm 5.2 \%$. Number of LTC-IC in uncultured UCB CD34 ${ }^{+}$cells $=0.6 \% \pm 0.1 \%$. Results are derived from 2 to 3 independent experiments.

*AFT024-noncontact culture with FL, SCF, and IL-7 or FL and Tpo (see "Materials and methods" for concentrations).

†Stroma-free culture contained granulocyte colony-stimulating factor (G-CSF), macrophage-inflammatory protein-1 $\alpha$ (MIP1- $\alpha$ ), IL-6, monocyte-chemoattractant protein-1 (MCP-1), vascular endothelial cell growth factor (VEGF), IL-8, N-desulfated, O-sulfated heparin, Tpo, FL, SCF, and IL-7 (see "Materials and methods" for concentrations).

SNC indicates stroma-noncontact. See Table 1 for other abbreviations.

effect of cell dose on the level of engraftment was seen. The SRC frequency was $4.0 / 10^{5} \mathrm{CD}^{+}{ }^{+}$cells $(2.4-6.7,95 \%$ confidence limits). Thus, SRC frequency as well as level of engraftment of $\mathrm{UCB}$ CD $34^{+}$cells is maintained following culture in an AFT024 noncontact system with FL + SCF + IL-7 for at least 14 days.

We next compared the ability of AFT024 noncontact cultures supplemented with FL, SCF, and IL-7 to support SRC with a similar system supplemented with FL and Tpo. The latter combination is superior to an FL, SCF, and IL-7 containing AFT024 noncontact system in expanding primitive myeloid and lymphoid progenitors from UCB ${ }^{26} \mathrm{We}$ also tested a stroma-free system as a preliminary step toward producing a more clinically applicable system. Cultures were established and after 7 and 14 days, we examined the number of nucleated cells, CD $34^{+}$cells, CFC, LTC-IC, and SRC (Tables 2 and 3).

Culture of $\mathrm{UCB} \mathrm{CD} 34^{+}$cells in AFT024 noncontact with FL, SCF, IL-7 produced a 76-fold increase in total nucleated cells (TNC) with associated 16-fold increase in $\mathrm{CD}^{+} 4^{+}$cells at day 14 Culture of UCB CD34+ ${ }^{+}$cells in AFT024 noncontact with FL and Tpo yielded a 37-fold expansion in TNC and 8-fold expansion of $\mathrm{CD} 34^{+}$cells after 14 days. Culture in MV8 stroma-free cultures led to a 180 -fold expansion of TNC by day 14 , whereas $\mathrm{CD}^{+} 4^{+}$cells expanded only 2-fold. CFC and LTC-IC expansion was similar for all groups (Table 2).
Mice were injected with 4 doses $\left(25,50,75\right.$, and $100 \times 10^{3}$ cells) of uncultured UCB CD $34^{+}$cells. The mean engraftment levels were $13.1 \%, 9.0 \%, 4.7 \%$, and $2.4 \%$, respectively (Table 3 ). The SRC frequency was $3.8 / 10^{5}$ uncultured $\mathrm{CD} 34^{+}$cells. The same doses of $\mathrm{CD}_{3} 4^{+}$were cultured for 7 and 14 days in each of the 3 culture conditions and progeny transplanted. Engraftment results after 7 and 14 days of culture in each of the conditions tested are summarized in Table 3. Consistent with what we describe above, the SRC frequencies in $\mathrm{CD} 34^{+}$cells cultured in FL, SCF, and IL-7 AFT024 culture conditions were $8.3 / 10^{5} \mathrm{CD} 34^{+}$cells and 3.6/10 $\mathrm{CD}_{3} 4^{+}$cells on days 7 and 14, respectively. SRC frequencies in FL and Tpo conditions were $3.2 / 10^{5} \mathrm{CD} 34^{+}$cells and $7.2 / 10^{5} \mathrm{CD} 34^{+}$ cells on days 7 and 14, respectively. When cells were cultured in stroma-free cultures for 7 days, the SRC frequency was $1.2 / 10^{5}$ CD $34^{+}$cells, and after 14 days, $6.1 / 10^{5} \mathrm{CD} 34^{+}$cells. Levels of human engraftment were similar for the 3 culture conditions.

Studies from our laboratory indicate that expansion of primitive LTC-IC and NK-IC in AFT024-noncontact cultures supplemented with FL and Tpo is greater at 5 than 2 weeks. ${ }^{26}$ Similar results have been described by Piacibello and coworkers. ${ }^{34}$ We therefore tested whether engrafting cells could be maintained for longer periods in AFT024 noncontact culture with FL and Tpo or FL, SCF, and IL-7. After culture for 28 days, 3 of 5 mice transplanted with the progeny of $10^{5} \mathrm{CD} 34^{+} \mathrm{UCB}$ cells expanded in FL and Tpo engrafted at

Table 3. Engraftment of freshly thawed and ex vivo expanded umbilical cord blood CD $34^{+}$cells in different culture conditions

\begin{tabular}{|c|c|c|c|c|c|c|c|c|c|c|c|c|c|c|}
\hline & & \multirow[b]{2}{*}{ Day 0} & \multicolumn{6}{|c|}{ Day 7} & \multicolumn{6}{|c|}{ Day 14} \\
\hline & & & \multicolumn{2}{|r|}{ FS7-SNC $\ddagger$} & \multicolumn{2}{|r|}{ FT-SNC $\ddagger$} & \multicolumn{2}{|c|}{ Stroma free§ } & \multicolumn{2}{|r|}{ FS7-SNC $\ddagger$} & \multicolumn{2}{|r|}{ FT-SNC $\ddagger$} & \multicolumn{2}{|c|}{ Stroma free§ } \\
\hline \multicolumn{15}{|l|}{ Cell dose $\times 10^{3} \|$} \\
\hline 50 & $7 / 7$ & $4.7 \pm 1.3$ & $8 / 8$ & $5.6 \pm 1.8$ & $7 / 8$ & $8.7 \pm 3.5$ & $4 / 5$ & $2.4 \pm 1.9$ & $4 / 6$ & $6.3 \pm 3.6$ & $6 / 6$ & $8.1 \pm 3.1$ & $3 / 3$ & $4.3 \pm 1.3$ \\
\hline 75 & $4 / 6$ & $9.0 \pm 4.2$ & $4 / 4$ & $7.1 \pm 5.6$ & $5 / 6$ & $7.8 \pm 4.0$ & $3 / 4$ & $3.5 \pm 2.2$ & $5 / 5$ & $20.4 \pm 10.2$ & $5 / 5$ & $7.0 \pm 2.3$ & $4 / 4$ & $4.5 \pm 2.8$ \\
\hline 100 & $7 / 7$ & $13.1 \pm 3.4$ & $6 / 6$ & $15.8 \pm 2.9$ & $3 / 3$ & $9.7 \pm 5.5$ & $2 / 4$ & $14.0 \pm 10.4$ & $4 / 4$ & $11.6 \pm 10.1$ & $6 / 6$ & $15.5 \pm 5.0$ & $2 / 2$ & $9.5 \pm 5.5$ \\
\hline $\mathrm{SRC} / 10^{5}$ cells & & $3.8(2.2-6.5)$ & & $6.5(3.4-12.5)$ & & $3.2(1.8-5.7)$ & & $1.4(0.7-2.7)$ & & $3.6(2-6.4)$ & & $7.2(3.2-16.6)$ & & $6.1(2.4-15.6)$ \\
\hline CD14\# & & $17.5 \pm 4.4$ & & $24.1 \pm 4.3$ & & $16 \pm 4.6$ & & $5.0 \pm 1.0$ & & $19.8 \pm 3.6$ & & $12 \pm 0.4$ & & $15.3 \pm 2.6$ \\
\hline CD19 & & $48.8 \pm 7.7$ & & $31.3 \pm 5.3$ & & $47.7 \pm 5.2$ & & $71 \pm 2.0$ & & $33.3 \pm 6.9$ & & $54.3 \pm 1.5$ & & $46 \pm 3.1$ \\
\hline CD33 & & $42.0 \pm 7.0$ & & $55.9 \pm 5.8$ & & $40.3 \pm 2.3$ & & $25 \pm 9.0$ & & $50.2 \pm 7.8$ & & $31.5 \pm 3$ & & $40 \pm 2.6$ \\
\hline CD34 & & $13.8 \pm 1.0$ & & $10.6 \pm 1.6$ & & $15.3 \pm 2.7$ & & $29.5 \pm 4.5$ & & $12.3 \pm 2.9$ & & $15.8 \pm 1.8$ & & $13 \pm 2.1$ \\
\hline
\end{tabular}

$\mathrm{UCB} \mathrm{CD} 34^{+}$cells were cultured in AFT024-noncontact culture or stroma-free culture as described in "Materials and methods." After 1 and 2 weeks, cell were harvested and transplanted in limiting dilutions in sublethally irradiated NOD-SCID mice as described in "Materials and methods." After 6 weeks, animals were killed and evaluated for human engraftment.

See Tables 1 and 2 for abbreviations.

*Number of animals engrafted/number of animals that were transplanted.

†Mean \pm SEM percent human CD45+ cells in mouse marrow.

¥AFT024-noncontact culture with $10 \mathrm{ng} / \mathrm{mL}$ FL, $10 \mathrm{ng} / \mathrm{mL} \mathrm{SCF}$, and $10 \mathrm{ng} / \mathrm{mL}$ IL-7 or $10 \mathrm{ng} / \mathrm{mL}$ FL and $10 \mathrm{ng} / \mathrm{mL}$ TPO.

§Stroma-free culture contained G-CSF, MIP 1- $\alpha$, IL-6, MCP-1, VEGF, IL-8, N-desulfated, O-sulfated heparin, Tpo, FL, SCF, and IL-7 engraftment.

|Determination of SCID repopulating cell (SRC) frequency (see "Materials and methods").

ๆCells were further analyzed by flow cytometry to demonstrate multilineage differentiation.

\#Engraftment data and SRC frequency are derived from 2 independent experiments with 2 to 4 mice being analyzed at each dose and time point. Multilineage potential is the mean \pm SEM of 2 to 4 mice. 
levels of $2 \%, 2 \%$, and $3 \%$. At a cell dose of $5 \times 10,41$ of 2 mice engrafted at a level of $3 \%$. Two of 2 mice transplanted with the progeny of $10^{5}$ cells expanded for 28 days in FL, SCF, and IL-7 engrafted at levels of $2 \%$ and $3 \%$.

To demonstrate that primitive progenitors engrafted, we examined if multilineage engraftment was obtained and whether cells could be serially passaged to secondary and tertiary recipients. No $\mathrm{CD}^{+} \mathrm{T}$ cells were detected in animals that received either day 0 , day 7 , or day 14 engrafted cells. However, $17.5 \%$ of human CD $45^{+}$ cells from day 0 engrafted cells were $\mathrm{CD} 14^{+}, 48.8 \% \mathrm{CD}^{+} 9^{+}, 42 \%$ $\mathrm{CD}_{3}{ }^{+}$, and $13.8 \% \mathrm{CD}^{+} 4^{+}$(Figure 2 and Table 3). Culture in an AFT024 noncontact system supplemented with either FL, SCF, and IL-7, or FL and Tpo, or culture in a stroma-free system resulted in a similar distribution of each marker.

We next tested whether human cells could be transferred to secondary and tertiary NOD-SCID mice. All BM cells obtained from 2 femurs and 2 tibiae of single primary NOD-SCID animals that had more than $2 \%$ human $\mathrm{CD} 45^{+}$cells were transplanted into single secondary NOD-SCID animals (1:5 dilution). Eighteen animals received cells from animals engrafted with uncultured CD $34^{+}$cells, 18 mice received cells from animals engrafted with 7-day AFT024 noncontact cultured cells, and 17 mice received cells from animals engrafted with 14-day AFT024 noncontact cultured cells, and 2 and 2 animals received cells from primary recipients transplanted with cells expanded for 7 and 14 days, respectively, in stroma-free MV8 conditions. Human CD45 ${ }^{+}$cells at levels between $0.6 \%$ and $2 \%$ were found in 4 of 8 animals that received cells from primary recipients engrafted with noncultured cells. Six of 18 ( 5 of 11 FL + SCF + IL-7 and 1 of 7 FL + Tpo) mice who received day-7 cells from AFT024 noncontact culture engrafted at levels of $1 \%$ to $5 \%$. Eight of 17 mice (4 of 9 FL + $\mathrm{SCF}+\mathrm{IL}-7$ and 4 of $8 \mathrm{FL}+\mathrm{Tpo}$ ) who received day 14 cells engrafted at levels between $0.5 \%$ to $20 \%$. One percent human $\mathrm{CD} 45^{+}$cells were detected in the secondary recipient of cells recovered from one animal transplanted with day-7 MV8 stromafree cultured $\mathrm{CD}_{3} 4^{+}$cells and no engraftment was seen in secondary recipients of day 14 MV8 stroma-free cultured CD34 $4^{+}$ cells. Marrow from the 2 femurs and 2 tibiae from 9 secondary transplant recipients with more than $1 \%$ human $\mathrm{CD} 45^{+}$cells in the marrow were transplanted into tertiary NOD-SCID recipients. No engraftment was seen irrespective of the initial source of the cells.

To further confirm these results and to evaluate if different in vivo xenogeneic transplantation models measure similar cells, we also tested the ability of uncultured and culture-expanded UCB $\mathrm{CD} 4^{+}$cells to engraft preimmune fetal sheep. Cells were cultured in AFT024 noncontact conditions with FL, SCF, and IL-7 for 7 and 14 days. In the first set of experiments, pooled UCB was used to test the capacity of the cultured cells to engraft in primary recipients and to be serially passaged from primary to secondary and tertiary fetal sheep recipients. The results of these experiments are summarized in Table 4 . Fetal sheep transplanted with $10^{5}$ uncultured $\mathrm{CD}_{3} 4^{+}$cells (group I) had $4.8 \% \pm 0.7 \%$ human $\mathrm{CD} 45^{+}$ cells in the marrow 2 months after transplantation and this persisted for at least 6 months $\left(4.1 \% \pm 0.5 \%\right.$ human $\mathrm{CD}^{2} 5^{+}$cells $)$. Fetal sheep transplanted with day 7 cultured cells (group II) had $6.3 \% \pm 1.4 \%$ human $\mathrm{CD} 45^{+}$cells at 2 months and $4.3 \% \pm 0.9 \%$ human $\mathrm{CD}_{4} 5^{+}$cells at 6 months. Fetal sheep transplanted with day-14 cultured cells (group III) engrafted at $5.6 \% \pm 0.5 \%$ human $\mathrm{CD} 45^{+}$cells at 2 months, but this fell to $0.2 \% \pm 0.2 \%$ human $\mathrm{CD} 45^{+}$cells at 6 months. A second experiment was done in which $5 \times 10^{4} \mathrm{CD}_{3} 4^{+}$cells, fresh or after day 7 or day 14 of culture, from a single UCB were transplanted into preimmune fetuses (groups X,

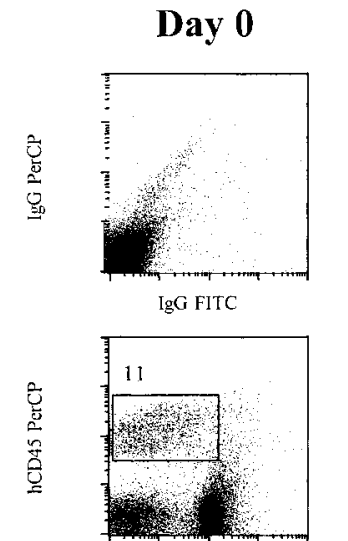

Day 7

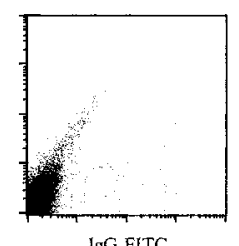

IgG FITC

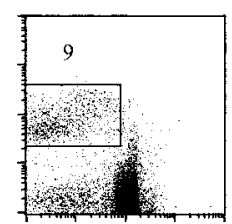

mCD45 FITC

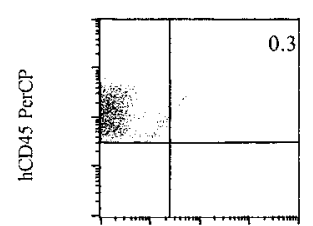

hCD3 PE

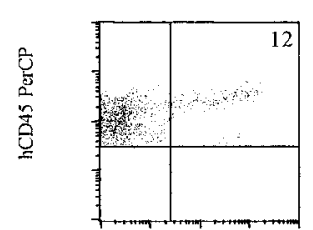

hCD14 PE
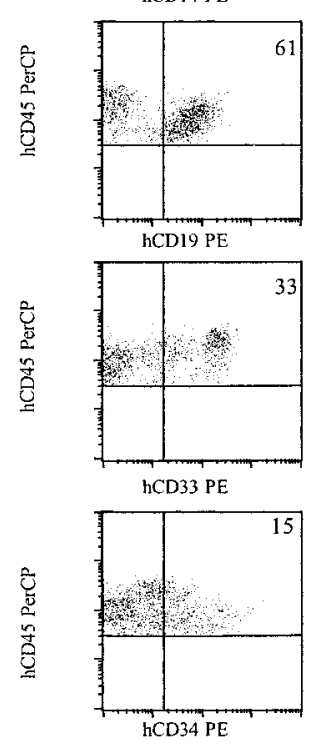

Figure 2. Cells cultured for 7 or 14 days in AFT02 after transplantation, BM was obtained from the femurs and tibiae of NOD/SCID mice and assessed for multilineage human engraftment by 3-color flow cytometry. Cells were initially gated on both the myeloid and lymphoid fractions. Isotype-matched controls are demonstrated in the top row. Cells that expressed human specific CD45 PerCP and were negative for murine specific CD45 FITC were then gated (second row). Expression of human-specific CD3 PE, CD14 PE, CD19 PE, CD33 PE, and CD34 PE was evaluated. Expanded cells expressed similar levels of each marker compared as day 0 cells (Table 3 ). IgG indicates immunoglobulin $\mathrm{G}$.

XI, XII) (Table 4). Two months after transplantation, animals were killed and human cell engraftment evaluated. Again, similar levels of human cell engraftment were seen for uncultured and ex vivoexpanded cells. 
From www.bloodjournal.org at kuleuven on October 6, 2010. For personal use only.

Table 4. Engraftment in the fetal sheep model

\begin{tabular}{|c|c|c|c|c|c|c|c|c|c|c|c|c|c|}
\hline \multirow[b]{3}{*}{ Cell dose } & \multicolumn{6}{|c|}{$1^{\circ}$ Recipient } & & & & & & & \\
\hline & \multirow[b]{2}{*}{ Group } & \multirow[b]{2}{*}{$\mathrm{N}$} & \multicolumn{2}{|c|}{$\%$ Engraftment } & \multirow[b]{2}{*}{$\mathrm{CD} 45^{+} \times 10^{4 *}$} & \multirow[b]{2}{*}{$\% \mathrm{CD} 4^{+}$} & \multicolumn{4}{|c|}{$2^{\circ}$ Recipient } & \multicolumn{3}{|c|}{$3^{\circ}$ Recipient } \\
\hline & & & $2 \mathrm{mo \ddagger}$ & $6 \mathrm{mo} \S$ & & & Group & $\mathrm{N}$ & $\%$ Engraftmentł & $\mathrm{MNC} \times 10^{6} \dagger$ & Group & $\mathrm{N}$ & $\%$ Engraftmentł \\
\hline $1 \times 10^{5}$ & I & 4 & $4.8 \pm 0.7$ & $4.1 \pm 0.5$ & 1.9 & 17.2 & IV & 3 & 5.2 & 5.1 & VII & 3 & 4.7 \\
\hline D7 cultured & II & 4 & $6.3 \pm 1.4$ & $4.3 \pm 0.9$ & 2.3 & 13.9 & V & 3 & 4.4 & 3.9 & VIII & 3 & 0.80 \\
\hline D14 cultured & III & 4 & $5.6 \pm 0.5$ & $0.2 \pm 0.2$ & 1.7 & 7.2 & VI & 3 & $<0.05$ & 4.2 & IX & 3 & 0 \\
\hline $5 \times 10^{4}$ & $x$ & 4 & 3.7 & ND & 3.3 & 11.3 & & & & & & & \\
\hline D14 cultured & XII & 4 & 1.7 & ND & 1.8 & 5.3 & & & & & & & \\
\hline
\end{tabular}

Fetal sheep were transplanted with fresh or ex vivo-cultured UCB CD34+ cells from multiple donors (group I-III) or a single donor (group X-XII). After 2 or 6 months, marrow was obtained and the frequency of human $\mathrm{CD}_{4} 5^{+}$cells determined by flow cytometry. As described in "Materials and methods," $\mathrm{CD} 45^{+}$cells or bone marrow mononuclear cells (BMMNC) were then transferred to secondary and tertiary recipients, respectively. These secondary and tertiary recipients were killed after 2 months and human cell engraftment determined. Results are derived from a single experiment.

${ }^{*}$ Total number of $\mathrm{CD} 45^{+}$cells recovered from 2 fetal sheep. These cells were split and given to 3 secondary recipients.

tTotal number of BMMNC cells recovered from 3 secondary recipients. These cells were split and given to 3 tertiary recipients.

$\ddagger$ Engraftment (mean \pm SEM) of 2 fetal sheep killed at 2 months after transplantation.

$\S$ Engraftment (mean \pm SEM) of 2 sheep at 6 months after transplantation.

ND indicates not determined.

We also examined if human cells could be serially transplanted in secondary and tertiary recipients as another measure for long-term engrafting cells. Secondary and tertiary fetal sheep recipients were evaluated 2 months after transplantation. Marrow of secondary (group IV) and tertiary (group VII) recipients of uncultured cells had $5.2 \%$ and $4.7 \%$ human $\mathrm{CD} 45^{+}$cells, respectively, at 2 months. Marrow of secondary (group V) and tertiary (group VIII) recipients of day-7 cultured cells had $4.4 \%$ and $0.8 \%$ human $\mathrm{CD} 45^{+}$cells, respectively, at 2 months. Again, multilineage engraftment was seen (Figure 3). Marrow of secondary recipients
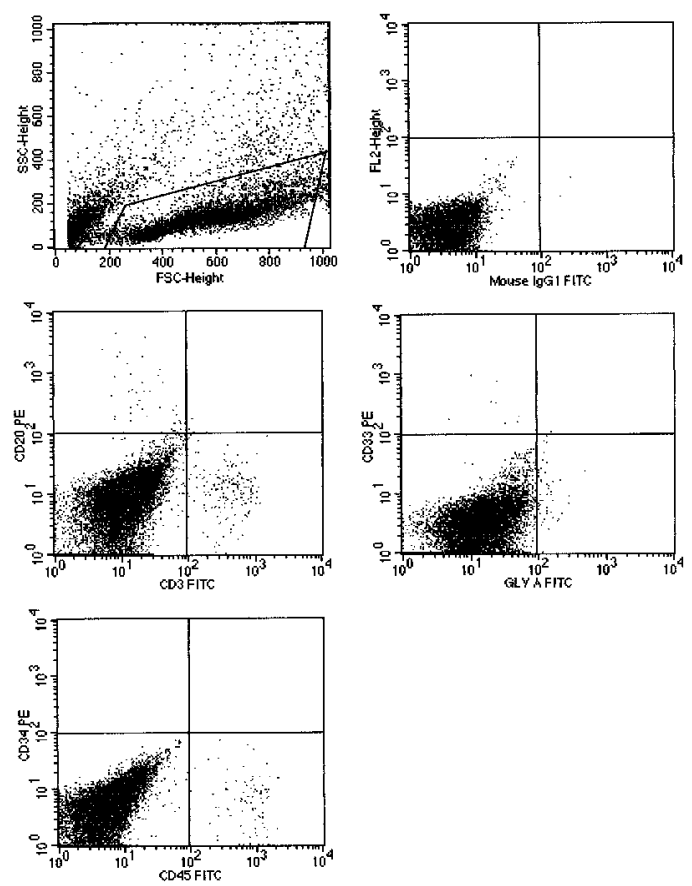

Figure 3. Cells cultured for 7 AFT024 in noncontact culture with FL + SCF + II-7 produce multilineage engraftment in tertiary fetal sheep recipients. CB CD34 ${ }^{+}$ cells (100 000), cultured in AFT024 noncontact culture for 7 days were injected into 4 fetal sheep. Sixty days after transplantation, 2 fetuses were killed and the human CD $45^{+}$cells pooled and then injected into 3 secondary recipients. These recipients were killed at 60 days, BM pooled, and injected into 3 tertiary recipients. After 60 days, fetuses were killed and the marrow obtained and assessed for multilineage human engraftment by 2-color flow cytometry. Cells were stained with antihumanCD45, CD20, CD3, CD33, CD34, and glyophorin-A antibodies. Isotype-matched controls are demonstrated in the top right. SSC indicates side scatter; FSC, forward scatter; FL2, fluorochrome 2 . of day-14 cultured cells (group VI) had less than $0.5 \%$ human $\mathrm{CD} 45^{+}$cells and no human cells could be detected in tertiary recipients of day-14 cultured cells (group IX). In all engrafted animals, multilineage hematopoiesis was seen (Table 5).

\section{Discussion}

Increased understanding of the regulatory processes involved in normal hematopoiesis has led to the development of a number of different culture systems aimed at expanding hematopoietic cell populations. A culture system that will expand HSC must increase the absolute number of primitive hematopoietic cells while maintaining their ability to produce multilineage progeny and repopulate myeloablated recipients. Several groups have developed stroma-free culture systems supplemented with multiple early acting cytokines. All but one study found limited expansion of cells capable of repopulating NOD-SCID mice or fetal sheep. ${ }^{15,20,21}$ Likewise, culture of progenitors on allogeneic human stromal feeders resulted in loss of engraftment capacity of both marrow and $\mathrm{UCB} \mathrm{CD} 34^{+}$cells. ${ }^{35}$

Several stromal feeders have been cloned that support longterm repopulating cells from murine, human, and primate sources. For instance, irradiated baboons were rescued when transplanted with autologous marrow cultured on a porcine microvascular cell line for 7 days. ${ }^{17}$ When cocultured with the murine stromal cell line, AC6.21, human $\mathrm{CD} 34^{+}$Thy $-1^{+}$cells continued to contain SRC. ${ }^{36}$ This suggests maintenance/expansion of at least short-term repopulating cells. Because studies were either in the autologous setting or without serial transplantation, it is not possible to assess whether HSC that can repopulate long-term were maintained/ expanded. One drawback of these culture systems is that cells are cultured in contact with the stromal layer, which would not be clinically applicable.

We have used a noncontact culture system as the basis for HSC expansion, and used 2 in vivo transplantation models in which cells are serially transferred to secondary and tertiary recipients to address the question of expansion of long-term engrafting cells. We used the AFT024 feeder, derived by Lemischka and colleagues from murine fetal liver. ${ }^{27}$ AFT024 cells support maintenance of competitive repopulating murine stem cells for more than 7 weeks as well as growth of LTC-IC, E-LTC-IC, NK-IC, and ML-IC. 10,23,25,37 We have previously reported that ex vivo culture of human UCB 
From www.bloodjournal.org at kuleuven on October 6, 2010. For personal use only.

Table 5. Expression of lineage markers (\%) or colony production (per $10^{5}$ cells) by engrafted human cells in fetal sheep: primary recipients (groups I, II, III) were examined 2 and 6 months after transplantation

\begin{tabular}{|c|c|c|c|c|c|c|c|c|c|c|c|c|}
\hline & \multicolumn{2}{|c|}{ Group I } & \multicolumn{2}{|c|}{ Group II } & \multicolumn{2}{|c|}{ Group III } & \multirow{2}{*}{$\begin{array}{c}\text { Group IV } \\
2 \mathrm{mo}\end{array}$} & \multirow{2}{*}{$\begin{array}{c}\text { Group V } \\
2 \mathrm{mo}\end{array}$} & \multirow{2}{*}{$\begin{array}{c}\text { Group VI } \\
2 \mathrm{mo}\end{array}$} & \multirow{2}{*}{$\begin{array}{c}\text { Group VII } \\
2 \mathrm{mo}\end{array}$} & \multirow{2}{*}{$\begin{array}{l}\text { Group VIII } \\
2 \text { mo }\end{array}$} & \multirow{2}{*}{$\begin{array}{c}\text { Group IX } \\
2 \text { mo }\end{array}$} \\
\hline & $2 \mathrm{mo}$ & $6 \mathrm{mo}$ & $2 \mathrm{mo}$ & $6 \mathrm{mo}$ & $2 \mathrm{mo}$ & $6 \mathrm{mo}$ & & & & & & \\
\hline CD3 & 0.72 & 0.51 & 2.1 & 0.80 & 0.30 & 0 & 0.78 & 0.15 & 0 & 0.22 & 0.08 & 0 \\
\hline CD20 & 0.66 & 0.50 & 0.70 & 0 & 0 & 0 & 0.50 & 0.28 & 0 & 0.53 & 0 & 0 \\
\hline CD33 & - & 0.48 & 1.12 & 1.40 & 0.50 & 0 & 1.08 & 0.77 & 0 & 0.60 & 0.23 & 0 \\
\hline CD34 & 0.32 & 0.18 & 0.20 & 0.09 & 0 & 0 & 0.15 & 0.09 & 0 & 0.19 & $<0.05$ & 0 \\
\hline CD45 & 4.8 & 4.1 & 6.3 & 4.3 & 5.6 & 0.18 & 5.20 & 4.40 & $<0.05$ & 4.7 & 0.80 & 0 \\
\hline Gly A & 14.6 & 8.9 & 7.8 & 9.3 & 9.2 & & 8.6 & 5.3 & 0.48 & 4.3 & 2.6 & 0 \\
\hline CFU-GM & 9.8 & 8.4 & 15.6 & 11.7 & 11.7 & 0 & 9.1 & 5.2 & 0 & 7.0 & 2.5 & 0 \\
\hline CFU-Mix & 4.9 & 5.2 & 6.8 & 5.9 & 6.2 & 0 & 5.6 & 3.1 & 0 & 4.4 & 0 & \\
\hline
\end{tabular}

Fetal sheep were transplanted with fresh or ex vivo-cultured UCB CD34+ cells from multiple donors. After 2 or 6 months, marrow was obtained and the frequency of human CD $45^{+}$cells determined by FACS. As described in "Materials and methods," CD45 cells or BMMNC cells were then transferred to secondary and tertiary recipients, respectively. These secondary and tertiary recipients were killed after 2 months and human cell engraftment determined.

Results are derived from a single experiment. Data from groups I to III are the mean results of 2 sheep. Data from groups IV to IX are the mean results from 3 sheep.

CFU-GM indicates colony-forming units-granulocyte macrophage.

$\mathrm{CD} 34^{+} \mathrm{Lin}^{-} \mathrm{CD} 38^{-}$cells in AFT024 noncontact cultures supplemented with FL + SCF + IL-7 results in a 3- to 5-fold expansion of LTC-IC and NK-IC after 2 and 5 weeks. ${ }^{26}$ We now show that when $\mathrm{UCB} \mathrm{CD} 34^{+}$cells were cultured in AFT024-noncontact cultures containing FL + SCF + IL-7, SRC frequency increases 1.3- to 2-fold after 7 and 14 days of culture. We did not detect significant differences when cells were cultured in the presence of FL + Tpo rather than FL + SCF + IL-7. Interestingly, we have previously shown that the FL + Tpo cytokine combination is superior at expanding LTC-IC and NK-IC over FL + SCF + IL-7. ${ }^{26}$ The discordance between results from in vitro LTC-IC and NK-IC assays and in vivo NOD-SCID engraftment assays may indicate that these assays measure cells at a slightly different stage of differentiation. Alternatively, homing may be more defective in the absence of SCF in the expansion medium, leading to a further underestimation of SRC in cultures without this cytokine. ${ }^{38} \mathrm{Cul}-$ tured SRC had multilineage differentiation ability, and more importantly, were able to engraft secondary NOD-SCID mice, thus confirming that the AFT024-noncontact system maintains human progenitors that can repopulate recipients for at least 6 months. Engrafting cells were lost when transferred to tertiary recipients, but this was true for cells that were transplanted before or after ex vivo culture and may reflect the 1:5 dilution done with each transfer step and the sequential loss of progenitors due to the low seeding efficiency of SRC. ${ }^{46}$

To further demonstrate that the AFT024 noncontact system can maintain/expand HSC, we transplanted uncultured and ex vivoexpanded UCB CD $34^{+}$cells in preimmune fetal sheep. This also provided us with the unique opportunity to compare the 2 xenogeneic transplantation models. Although the NOD-SCID model may be the most commonly used assay to measure engrafting human cells, a number of studies suggest that serial transplantation to examine presence of long-term repopulating cells is more easily achieved in the fetal sheep than NOD-SCID model. ${ }^{15,39,40}$ Serial evaluation of marrow of sheep recipients for more than 6 months to several years, which cannot be done in the NOD-SCID model, is another way to measure presence of longterm engrafting human cells. In addition, Civin and colleagues have demonstrated that serial transfer of human cells to secondary and tertiary fetal sheep recipients allows detection of the most primitive progenitors. They showed that in contrast to $\mathrm{CD} 34^{+} \mathrm{CD} 38^{-}$ progenitors, $\mathrm{CD} 38^{+} \mathrm{CD} 34^{+}$cells that engraft in primary sheep recipients cannot be transferred to subsequent recipients model. ${ }^{14}$ This coincided with the ability of $\mathrm{CD} 34^{+} \mathrm{CD} 38^{-}$but not
$\mathrm{CD} 34^{+} \mathrm{CD} 38^{+}$cells to give rise to human hematopoiesis for more than 1 year in the primary recipients.

We also evaluated "long-term" engraftment. We examined sheep 6 months after transplantation or transfer of cells into secondary and tertiary fetal sheep recipients. Cells cultured ex vivo in AFT024 cultures supplemented with FL + SCF + IL-7 could support high levels of human hematopoietic cell engraftment 6 months after transplantation and could be serially transferred to secondary and even tertiary sheep recipients. Cells cultured for 7 days ex vivo produced multilineage engraftment in primary recipients at 6 months and also in secondary and tertiary fetal sheep recipients. These findings, taken together with the data from the NOD/SCID model, strongly suggest that multilineage engrafting cells that persist for at least 6 months are at a minimum maintained in AFT024 noncontact cultures. In view of the report by Civin and coworkers, the finding that engrafting cells could be transferred to secondary and tertiary recipients suggests that long-term engrafting cells can be maintained. The degree of engraftment of cells cultured ex vivo for 7 days in the tertiary recipients was lower than that of uncultured cells. This may indicate that the frequency of long-term engrafting cells has declined somewhat during culture. However, no decreased engraftment was seen in the primary recipients at 6 months or in the secondary recipients. Limiting dilutions will be needed to determine the importance of this observation.

As we saw in the NOD-SCID model, day-14 expanded cells engrafted at 2 months in the fetal sheep model. Of note, serial transfer to secondary and tertiary sheep as well as assessment of the primary animals at 6 months showed that cells that could sustain human hematopoiesis for at least 6 months may decline significantly following 14 days of ex vivo expansion. This at first seems to contradict the results seen in the NOD-SCID model where no obvious differences were seen in secondary engraftment of day 7 and day 14 cultured cells. However, evaluation in the sheep model was at later time points than in the NOD-SCID model, as sheep are killed at 8 weeks rather than 6 weeks. Thus, our studies suggest that long-term engrafting cells may progressively decline with extended time in culture.

To make this system more clinically suitable, we examined if we could develop a stroma-free system that would reproduce results obtained in AFT024 noncontact cultures. The stroma-free system was developed based on knowledge gained on growth factors and extracellular matrix components present in stromaconditioned medium that are required for the support of LTCIC. ${ }^{29,30,41,42}$ We have previously reported on the importance of 
From www.bloodjournal.org at kuleuven on October 6, 2010. For personal use only.

specific 6-O-sulfated heparan-sulfate glycosaminoglycans for maintaining LTC-IC ex vivo. In addition, we have identified cytokines elaborated by human stromal feeders required for LTC-IC growth. We combined these components with 3 cytokines found to be present in nanogram concentrations in AFT024 supernatants (MCP-1, VEGF, and IL-8) (unpublished observation, 1999) and added a mixture of FL $+\mathrm{SCF}+\mathrm{IL}-7+$ Tpo. Consistent with previous studies from our group, ${ }^{29,41,42}$ a 2 - to 3-fold LTC-IC expansion was seen that is similar to that seen in AFT024 noncontact cultures. Engraftment was seen with day-7 and -14 expanded cells and the frequency in day-14 cultured cells was 1.6-fold higher than in uncultured cells. Engrafted cells maintained multilineage differentiation capacity, and in 1 of 4 animals tested, we found secondary transfer of human cells. Whether these cells can engraft in the fetal sheep model and support hematopoiesis in secondary and tertiary sheep or for protracted periods of time in primary sheep is currently under investigation. However, these initial results suggest that it may be possible to develop defined stroma-free systems based on knowledge gained on factors involved in hematopoietic regulation by AFT024 that will support maintenance/expansion of long-term engrafting human cells.

The variables involved in the engraftment of transplanted cells are not well understood. In particular, the role of cell dose and accessory cells in facilitating engraftment are variables we did not control in this study. Thus, animals receiving cells at day 7 and day 14 received much larger cell doses. Using a statistical model, van der Loo and coworkers demonstrated a dose-response relationship of mobilized peripheral blood $\mathrm{CD} 34^{+}$cells and engraftment. ${ }^{43}$ Using BM $34^{+} \operatorname{lin}^{-} 38^{-}$cells Bonnet and associates showed that low cell doses required cotransplantation of accessory cells but at doses of more than 5000 cells, accessory cells were not necessary. ${ }^{44}$ In the murine system, transplantation across allogeneic barriers is facilitated by the use of specific accessory cells. ${ }^{45,46}$ Whether these specific findings apply to UCB CD $34^{+}$cells cultured in our system remains to be determined.

In conclusion, we show for the first time that cells capable of "long-term" engraftment in fetal sheep or NOD-SCID mice can be preserved when cultured for 7 , and possibly 14 days, ex vivo in an AFT024 noncontact culture system or even a stroma-free system modeled on the AFT024 noncontact culture system. Culture methods described here should lead to the development of a clinically suitable culture system for ex vivo expansion, and allow for final demonstration that the conditions support long-term engraftment in human clinical trials.

\section{References}

1. Brenner M, Rill D, Holladay M et al. Gene marking to determine whether autologous marrow infusion restores long-term haemopoiesis in cancer patients. Lancet. 1993;342:1134-1137.

2. Kohn DB, Hershfield MS, Carbonaro D, et al. T lymphocytes with a normal ADA gene accumulate after transplantation of transduced autologous umbilical cord blood CD34+ ${ }^{+}$cells in ADA-deficient SCID neonates. Nat Med. 1998;4:775-780.

3. Sellers S, Tisdale J, Bodine D, et al. No discrepancy between in vivo gene marking efficiency assessed in peripheral blood populations compared with bone marrow progenitors or CD34+ cells. Hum Gene Ther. 1999:10:633-640.

4. Barnett MJ, Eaves CJ, Phillips GL, et al. Autografting with cultured marrow in chronic myeloid leukemia: results of a pilot study. Blood. 1994:84: 724-732.

5. Verfaillie C, Miller W, Boylan K, McGlave P. Selection of benign primitive hematopoietic progenitors in chronic myelogenous leukemia on the basis of HLA-DR antigen expression. Blood. 1992; 79:1003-1010.

6. Cairo MS, Wagner JE. Placental and/or umbilical cord blood: an alternative source of hematopoietic stem cells for transplantation. Blood. 1997; 90:4665-4678.

7. Rubinstein P, Carrier C, Scaradavou A, et al. Outcomes among 562 recipients of placental-blood transplants from unrelated donors. N Engl J Med. 1998;339:1565-1577.

8. Sutherland H, Eaves C, Eaves A, Dragowska W, Landsdorp PM. Characterization and partial purification of human marrow cells capable of initiating long-term hematopoiesis in vitro. Blood. 1989; 74:1563-1570.

9. Hao QL, Thiemann FT, Petersen D, Smogorzewska EM, Crooks GM. Extended long-term culture reveals a highly quiescent and primitive human hematopoietic progenitor population. Blood. 1996;88:3306-3313

10. Punzel M, Wissink S, Miller J, Moore K, Lemischka I, Verfaillie C. The myeloid-lymphoid initiating cell $(\mathrm{ML}-\mathrm{IC})$ assay assesses the fate of multipotent human progenitors in vitro. Blood. 1999; 93:3750-3756.

11. McCune JM, Namikawa R, Kaneshima H, Shultz LD, Lieberman M, Weissman IL. The SCID-hu mouse: murine model for the analysis of human hematolymphoid differentiation and function. Science. 1988;24:1632-1639.

12. Larochelle A, Vormoor J, Hanenberg $\mathrm{H}$, et al Identification of primitive human hematopoietic cells capable of repopulating NOD/SCID mouse bone marrow: implications for gene therapy. Nat Med. 1996;2:1329-1337.

13. Nolta JA, Hanley MB, Kohn DB. Sustained human hematopoiesis in immunodeficient mice by cotransplantation of marrow stroma expressing human interleukin-3: analysis of gene transduction of long-lived progenitors. Blood. 1994;83: 3041-3051.

14. Civin C, Almeida-Porada G, Lee M, Olweus J, Terstappen L, Zanjani E. Sustained, retransplantable, multilineage engraftment of highly purified adult human bone marrow stem cells in vivo. Blood. 1996;88:4102-4109.

15. Shimizu Y, Ogawa M, Kobayashi M, Almeida-Porada G, Zanjani ED. Engraftment of cultured human hematopoietic cells in sheep. Blood. 1998; 91:3688-3692.

16. Tisdale JF, Hanazono Y, Sellers SE, et al. Ex vivo expansion of genetically marked rhesus peripheral blood progenitor cells results in diminished long-term repopulating ability. Blood. 1998;92: 1131-1141.

17. Brandt JE, Bartholomew AM, Fortman JD, et al. Ex vivo expansion of autologous bone marrow CD34(+) cells with porcine microvascular endothelial cells results in a graft capable of rescuing lethally irradiated baboons. Blood. 1999;94:106113.

18. Reiffers J, Cailliot C, Dazey B, Attal M, Caraux J, Boiron JM. Abrogation of post-myeloablative chemotherapy neutropenia by ex-vivo expanded autologous CD34-positive cells. Lancet. 1999;354: 1092-1093.

19. McNiece I, Jones R, Cagnoni P, Bearman S, Nieto Y, Shpall EJ. Ex-vivo expansion of hematopoietic progenitor cells: preliminary results in breast cancer. Hematol Cell Ther. 1999:41:82-86.

20. Conneally E, Cashman J, Petzer A, Eaves C. Expansion in vitro of transplantable human cord blood stem cells demonstrated using a quantitative assay of their lympho-myeloid repopulating activity in nonobese diabetic-scid/scid mice. Proc Natl Acad Sci U S A. 1997;94:9836-9841.

21. Bhatia M, Bonnet D, Kapp U, Wang JC, Murdoch
B, Dick JE. Quantitative analysis reveals expansion of human hematopoietic repopulating cells after short-term ex vivo culture. J Exp Med. 1997 186:619-624.

22. Piacibello W, Sanavio F, Severino A, et al. Engraftment in nonobese diabetic severe combined immunodeficient mice of human CD $34^{+}$cord blood cells after ex vivo expansion: evidence for the amplification and self-renewal of repopulating stem cells. Blood. 1999;93:3736-3749.

23. Arakawa-Hoyt ST, Thiemann FT, Dao MA, Barsky L, Crooks GM, Nolta JA. The AFT024 stromal cell line supports long-term ex-vivo maintenance of engrafting multipotent human hematopoietic progenitors. Blood. 1998;92:2379a.

24. Robin C, Pflumio F, Vainchenker W, Coulombel L Identification of lymphomyeloid primitive progenitor cells in fresh human cord blood and in the marrow of nonobese diabetic-severe combined immunodeficient (NOD-SCID) mice transplanted with human CD34(+) cord blood cells. J Exp Med. 1999;189:1601-1610.

25. Moore KA, Hideo E, Lemischka IR. In vitro maintenance of highly purified transplantable hematopoietic stem cells. Blood. 1997;89:4337-437.

26. Lewis ID, Verfaillie CM. Multi-lineage expansion potential of primitive hematopoietic progenitors: superiority of umbilical cord blood compared to mobilized peripheral blood. Exp Hematol. 2000; 28:1087-1095.

27. Wineman J, Moore K, Lemischka I, MullerSieburg C. Functional heterogeneity of the hematopoietic microenvironment: rare stromal elements maintain long-term repopulating stem cells. Blood. 1996;87:4082-4090.

28. Verfaillie $\mathrm{C}$. Direct contact between progenitors and stroma is not required for human in vitro hematopoiesis. Blood. 1992;79:2821-2826.

29. Gupta P, Oegema T, Verfaillie C. Differences in the LTC-IC maintaining capacity of stromal cells correlates with patterns of sulfation of their heparan sulfate glycosaminoglycans. Blood. 1998:92; 4641-4651.

30. Punzel M, Gupta P, Roodell A, Mortari F, Verfaillie C. Factor(s) secreted by AFT024 fetal liver cells following stimulation with human cytokines are important for human LTC-IC growth. Leukemia. 1999;13:1079-1084.

31. Verfaillie CM, McGlave PB. Leukemia inhibitory 
From www.bloodjournal.org at kuleuven on October 6, 2010. For personal use only.

factor/human interleukin for DA cells: a growth factor that stimulates the in vitro development of multipotential human hematopoietic progenitors. Blood. 1991;77:263-270.

32. Zanjani ED, Ascensao JL, Harrison MR, Tavassoli $M$. Ex vivo incubation with growth factors enhances the engraftment of fetal hematopoietic cells transplanted in sheep fetuses. Blood. 1992; 79:3045-3049

33. Srour EF, Zanjani ED, Cornetta K, et al. Persistence of human multilineage self-renewing lymphohematopoietic stem cells in chimeric sheep. Blood. 1993;82:3333-3342.

34. Piacibello W, Sanavio F, Garetto L, et al. Extensive amplification and self-renewal of human primitive hematopoietic stem cells from cord blood. Blood. 1997;89:2644-2653.

35. Gan O, Murdoch B, Larochelle A, Dick J. Differential maintenance of primitive human SCIDrepopulating cells clonogenic progenitors and long-term culture-initiating cells after incubation on human bone marrow stromal cells. Blood. 1997;90:641-651.

36. Shih CC, Hu MC, Hu J, Medeiros J, Forman SJ. Long-term ex vivo maintenance and expansion of transplantable human hematopoietic stem cells. Blood. 1999;94:1623-1636.
37. Miller J, McCullar V, Punzel M, Lemischka I, Moore K. Single adult human CD34(+)/Lin-/ CD38(-) progenitors give rise to natural killer cells, B-lineage cells, dendritic cells, and myeloid cells. Blood. 1999:93:96-106.

38. Peled A, Petit I, Kollet O, et al. Dependence of human stem cell engraftment and repopulation of NOD/SCID mice on CXCR4. Science. 1999;283: 845-848.

39. Zanjani ED, Almeida-Porada G, Livingston AG, Flake AW, Ogawa M. Human bone marrow CD34- cells engraft in vivo and undergo multilineage expression that includes giving rise to CD34+ cells. Exp Hematol. 1998;26:353-360.

40. Cashman J, Eaves C. Human growth factorenhanced regeneration of transplantable human hematopoietic stem cells in nonobese diabetic/ severe combined immunodeficient mice. Blood. 1999;93:481-487.

41. Gupta P, Oegema TJ, Brazil J, Dudek A, Slungaard A, Verfaillie C. Structurally specific heparan sulfates support primitive human hematopoiesis by formation of a multimolecular stem cell niche. Blood. 1998;92:4641-4651.

42. Gupta K, Gupta P, Solovey A, Hebbel RP. Mechanism of interaction of thrombospondin with human endothelium and inhibition of sickle erythro-cyte adhesion to human endothelial cells by heparin. Biochim Biophys Acta. 1999 1453:63-73.

43. van der Loo JC, Hanenberg H, Cooper RJ, Luo FY, Lazaridis EN, Williams DA. Nonobese diabetic/severe combined immunodeficiency (NOD/ SCID) mouse as a model system to study the engraftment and mobilization of human peripheral blood stem cells. Blood. 1998:92:2556-2570.

44. Bonnet D, Bhatia M, Wang JC, Kapp U, Dick JE. Cytokine treatment or accessory cells are required to initiate engraftment of purified primitive human hematopoietic cells transplanted at limiting doses into NOD/SCID mice. Bone Marrow Transplant. 1999;23:203-209.

45. el Badri NS, Good RA. Lymphohemopoietic reconstitution using wheat germ agglutinin-positive hemopoietic stem cell transplantation within but not across the major histocompatibility antigen barriers. Proc Natl Acad Sci U S A. 1993;90:6681 6685.

46. Gaines BA, Colson YL, Kaufman CL, Ildstad S. Facilitating cells enable engraftment of purified fetal liver stem cells in allogeneic recipients. Exp Hematol. 1996;24:902-913. 